University of Nebraska - Lincoln

DigitalCommons@University of Nebraska - Lincoln

Faculty Publications, Department of Psychology

Psychology, Department of

2009

\title{
Severity of Child Sexual Abuse and Revictimization: The Mediating Role of Coping and Trauma Symptoms
}

\author{
Michelle A. Fortier \\ University of California-Irvine \\ David DiLillo \\ University of Nebraska-Lincoln, ddilillo@unl.edu \\ Terri L. Messman-Moore \\ Miami University \\ James Peugh \\ University of Virginia \\ Kathleen A. DeNardi \\ Miami University \\ See next page for additional authors
}

Follow this and additional works at: https://digitalcommons.unl.edu/psychfacpub

Part of the Psychiatry and Psychology Commons

Fortier, Michelle A.; DiLillo, David; Messman-Moore, Terri L.; Peugh, James; DeNardi, Kathleen A.; and Gaffey, Kathryn J., "Severity of Child Sexual Abuse and Revictimization: The Mediating Role of Coping and Trauma Symptoms" (2009). Faculty Publications, Department of Psychology. 400.

https://digitalcommons.unl.edu/psychfacpub/400

This Article is brought to you for free and open access by the Psychology, Department of at DigitalCommons@University of Nebraska - Lincoln. It has been accepted for inclusion in Faculty Publications, Department of Psychology by an authorized administrator of DigitalCommons@University of Nebraska - Lincoln. 
Authors

Michelle A. Fortier, David DiLillo, Terri L. Messman-Moore, James Peugh, Kathleen A. DeNardi, and Kathryn J. Gaffey 
Published in Psychology of Women Quarterly 33:3 (2009), pp. 308-320; doi: 10.1111/j.1471-6402.2009.01503.x

Copyright ( 2009 Division 35, American Psychological Association. Used by permission. "This article may not exactly replicate the final version published in the APA journal. It is not the copy of record."

This research was supported in part by a grant awarded to the second author from the University of Nebraska-Lincoln Research Council.

The authors wish to thank the reviewers of the article manuscript for providing thought-provoking feedback that stimulated ideas they were able to incorporate into the paper.

Submitted March 10, 2008; accepted (initial) January 18, 2009; accepted (final) March 10, 2009; published online August 3, 2009.

\title{
Severity of Child Sexual Abuse and Revictimization: The Mediating Role of Coping and Trauma Symptoms
}

\author{
Michelle A. Fortier, Department of Anesthesiology and Perioperative Care, \\ University of California-Irvine, Children's Hospital of Orange County \\ David DiLillo, Department of Psychology, University of Nebraska-Lincoln \\ Terri L. Messman-Moore, Department of Psychology, Miami University \\ James Peugh, Curry School of Education, University of Virginia \\ Kathleen A. DeNardi and Kathryn J. Gaffey, Department of Psychology, Miami University \\ Corresponding author - Michelle A. Fortier, Children's Hospital of Orange County, \\ 505 S. Main St., Suite 940, Orange, CA 92868; email mfortier@choc.org
}

\begin{abstract}
Child sexual abuse (CSA) has consistently been associated with the use of avoidant coping; these coping methods have been associated with increased trauma symptoms, which have, in turn, been linked to increased risk for adult sexual revictimization. Given these previous findings, the purpose of the current study was to test a model that conceptualized the relationships among these variables. Specifically, CSA severity was conceptualized as leading to the use of avoidant coping, which was proposed to lead to maintenance of trauma symptoms, which would, in turn, impact severity of revictimization indirectly. This comprehensive model was tested in a cross-sectional study of a large, geographically diverse sample of college women. Participants were 99 female undergraduates classified as having experienced CSA who completed measures of abuse history, coping style, current levels of trauma symptoms, and adult sexual revictimization. Multivariate path analysis indicated that the data fit the hypothesized model for verbally coercive, but not physically aggressive, revictimization. Specifically, increased CSA severity was associated with the use of avoidant coping, which, in turn, predicted greater levels of trauma symptomatology and severity of sexual coercion in adulthood. Although cross-sectional in nature, findings from this study suggest that coping strategies and trauma symptoms may represent modifiable factors that place women at increased risk for verbally coercive sexual revictimization.
\end{abstract}

Estimates suggest that between one-fifth and one-third of women have experienced sexual abuse in their childhood (Elliott \& Briere, 1995; Finkelhor, 1994). Child sexual abuse (CSA) is a risk factor for the development of an array of long-term difficulties, including depression, anxiety disorders, dissociation, personality and eating disorders, and substance use disorders (Molnar, Buka, \& Kessler, 2001; for reviews, see Neumann, Houskamp, Pollock, \& Briere, 1996; Polusny \& Follette, 1995). Other associated problems are more interpersonal in nature, and include decreased trust and intimacy, decreased satisfaction in marital and other relationships (DiLillo, 2001), and increased risk for later victimization (Arata, 2002).
Revictimization is one of the most troubling outcomes associated with CSA because later victimization likely compounds or exacerbates the effects of prior abuse experiences. Although adult sexual victimization in the absence of child abuse may have its own detrimental impact, revictimization has been associated with increased levels of trauma symptoms compared to a single incident of sexual victimization (see Classen, Palesh, \& Aggarwal, 2005, for a review). In particular, women experiencing revictimization report higher levels of depression (Messman-Moore, Long, \& Siegfried, 2000), posttraumatic stress disorder (PTSD; Arata, 1999a; 1999b), other anxiety disorders (Cloitre, Scarvalone, \& Difede, 1997), 
dissociation (Cloitre et al., 1997), and alcohol use (Kilpatrick, Acierno, Resnick, Saunders, \& Best, 1997).

In searching for pathways from child maltreatment to revictimization, researchers have questioned whether the psychological difficulties so often linked to early abuse may contribute to this relationship. Specifically, avoidant coping strategies and trauma symptoms, including PTSD, are two constructs frequently examined in the association between CSA and revictimization. What does not appear to have been accomplished to date is an incorporation of these constructs into a single mediational model to explain the links between CSA, avoidant coping, trauma symptoms, and revictimization.

\section{CSA and Avoidant Coping}

Coping has long been considered an important process in understanding the short- and long-term functioning of individuals with a history of CSA. From a theoretical perspective, the experience of sexual trauma leads to efforts to adapt through various emotional and behavioral responses. These responses are often categorized as effective (e.g., directly addressing a problem) or ineffective (e.g., avoidance), although effectiveness may depend on several factors including timing and the nature of the stressor (Coyne \& Racioppo, 2000).

Substantial research suggests that CSA survivors often rely on avoidant coping strategies, including behavioral (e.g., spending more time alone) and emotional disengagement (e.g., criticizing self for what happened) both in the immediate aftermath of the abuse (DiPalma, 1994; Oaksford \& Frude, 2003) as well as into adulthood (Bonanno, Noil, Putnam, O'Neill, \& Trickett, 2003; Futa, Nash, Hansen, \& Garbin, 2003). Understandably, victims of CSA may avoid triggers of abuse-related emotions to prevent becoming overwhelmed with emotions that are too difficult to experience (Kleber \& Brown, 1992). Therefore, in the short-term, avoidance may be viewed as a necessary and healthy coping strategy. However, overemphasis on denial or avoidant coping can result in a sense of numbing or detachment, which can perpetuate psychological distress. Indeed, avoidant methods of coping have consistently been shown to relate to increased levels of psychological distress and trauma symptoms (Brand \& Alexander, 2003; Johnson \& Kenkel, 1991; Johnson, Sheahan, \& Chard, 2003; Leitenberg, Greenwald, \& Cado, 1992), even after controlling for the effects of characteristics of the abuse, such as abuse severity (Brand \& Alexander, 2003; Coffey, Leitenberg, Henning, Turner, \& Bennett, 1996; Leitenberg et al., 1992).

\section{Avoidant Coping and Trauma Symptoms}

There is evidence to support an increased focus on avoidant coping, rather than approach coping strategies, in understanding the link between traumatic experience and psychological distress. A recent meta-analysis indicated that avoidant coping has a greater impact than approach coping on psychological distress following traumatic experiences (Littleton, Horsley, John, \& Nelson, 2007). In cross-sectional studies, avoidant coping has been linked to greater levels of PTSD symptoms in numerous populations, including individuals with a history of interpersonal violence (Arias \& Pape, 1999), war veterans (Sutker, Davis, Uddo, \& Ditta, 1995), survivors of motor vehicle accidents (Bryant \& Harvey, 1995), and victims of sexual and nonsexual assault (Dunmore, Clark, \& Ehlers, 1999; Valentiner, Foa, Riggs, \& Gershuny, 1996). The negative impact of avoidant coping on symptomatology is also documented in longitudinal studies (Benotsch et al., 2000; Krause, Kaltman, Goodman, \& Dutton, 2008; Mellman, David, Bustamante, Fins, \& Esposito, 2001; Sharkansky, King, King, \& Wolfe, 2000). One of the most recent studies found that, among individuals with a history of domestic violence, avoidant coping predicted levels of PTSD up to one year later, even after controlling for the effects of CSA, interpersonal violence severity, social support, and revictimization (Krause et al., 2008).

A widely accepted conceptualization of PTSD symptoms is emotional processing theory (Foa \& Kozak, 1986), in which anxiety is hypothesized to result from associations of factors with the initial trauma. Similar to Mowrer's (1960) Two Factor Learning Theory, stress responses are hypothesized to develop through a learning process in which previously neutral stimuli are conditioned to produce strong emotional arousal in individuals through associations with the traumatic event (Foa \& Kozak, 1986; Keane, Fairbank, Caddel, Zimering, \& Bender, 1985; Litz \& Gray, 2002; Rausch \& Foa, 2006). This emotional response is similar to the arousal triggered during the trauma and, thus, provokes avoidance of the conditioned stimuli. For example, a woman who has been sexually assaulted may avoid the scene of the assault and any associated stimuli that provoke the strong, conditioned emotional response. Additionally, emotional processing theory posits that dysfunctional cognitions (e.g., "it is not safe to be alone") are associated with the maintenance of traumatic symptoms. Because of avoidance, individuals who have developed dysfunctional cognitions are not provided with disconfirming evidence; consequently, the thoughts persist and drive the avoidance and fear response. Thus, through operant conditioning, traumatic symptoms are maintained and perpetuated.

In addition to emotional avoidance, deliberate attempts to suppress unwanted trauma-related thoughts are also a form of avoidance that paradoxically increase the frequency of trauma-related thoughts and perpetuate reexperiencing symptoms (Shipherd \& Beck, 1999). Similarly, there is emerging evidence that thought suppression in the context of high levels of negative affect may exacerbate the development of PTSD symptoms among survivors of sexual assault (Rosenthal, Cheavens, Lynch, \& Follette, 2006). Thought suppression is 
linked to a broader class of avoidant coping behaviors that have been labeled "experiential avoidance." Experiential avoidance refers to any behavior that functions as an attempt to disconnect from aversive private experiences (e.g., emotions, sensations, memories, images) by actively taking steps to alter or reduce these experiences or the contexts in which they occur (Hayes, Strosahl, \& Wilson, 1999; Hayes, Wilson, Gifford, Follette, \& Strosahl, 1996). The existing literature suggests that, despite an initial benefit, long-term effects of experiential avoidance strategies are detrimental for individuals who have experienced sexual assault and rape (Batten, Follette, \& Aban, 2001; Boeschen, Koss, Figueredo, \& Coan, 2001) and that attempts to avoid unwanted thoughts may actually lead to an increase in such thoughts and a subsequent increase in psychological distress (Polusny, Rosenthal, Aban, \& Follette, 2004).

\section{Trauma Symptoms and Revictimization}

Both theoretical conceptualizations and empirical evidence of response to trauma support the notion that traumatic symptoms, including PTSD, become more persistent when individuals avoid trauma-related stimuli. PTSD symptomatology may interfere with information processing, risk perception, or self-protective responses (Chu, 1992) in a manner that increases risk for revictimization. For instance, if a survivor of sexual assault continually avoids physical and emotional reminders of the assault, she may fail to learn how to distinguish safe from potentially risky relationships or situations, increasing her vulnerability to revictimization. Maladaptive coping strategies, including avoidant strategies such as physical and emotional disengagement, as well as substance use and risky sexual behaviors, may be used to avoid sources of threat and reduce distress initially. However, because such fears are not extinguished, avoidance ultimately perpetuates a pervasive and heightened sense of threat. In addition to interfering with the process of extinction, avoidance strategies, including physical avoidance of trauma-related stimuli, suppression of unwanted thoughts, and other efforts to avoid psychological distress or harm, interfere with the correction of inaccurate or negative appraisals regarding safety and other aspects of traumatic experience (Ehlers \& Clark, 2000).

Symptoms of PTSD may have specific effects on the risk for revictimization. Dissociation, which is higher among revictimized than singly victimized women (Cloitre et al., 1997; Wilson, Calhoun, \& Bernat, 1999), may increase risk for revictimization by making survivors unaware of their environment or insensitive to potential cues regarding impending risk. Furthermore, dissociation may create a look of confusion or distraction, a state increasing vulnerability to sexual predators (Cloitre et al., 1997). Emotional flooding and numbing may impact revictimization by disrupting the appropriate fight-orflight response. PTSD is also characterized by intrusive re-experiencing, which alternates with states of emotional numbing, denial, and avoidance. Individuals frequently flooded with emotion may learn to ignore such high arousal states. Indeed, repeated victimization is associated with an overreaction to low-level threats and also a failure to react appropriately to a signal of threat or risk for assault (Cloitre \& Rosenberg, 2006). Chronic hyperarousal may also affect the chances of revictimization by negatively impacting the identification and labeling of feeling states. Alexithymia, which commonly accompanies PTSD (Badura, 2003; Yehuda et al., 1997; Zlotnick, Mattia, \& Zimmerman, 2001), may be particularly relevant to increased vulnerability for revictimization by known-assailants, where a diminished emotional vocabulary and an affectively out-of-sync self-representation may lead others to minimize or disregard refusals to engage in sexual activity (Cloitre \& Rosenberg, 2006).

Indeed, researchers have empirically documented that trauma symptoms and psychological distress may be potential explanations for why CSA survivors are at increased risk for revictimization. For instance, PTSD symptoms (Arata, 2000; Messman-Moore, Coates, Gaffey, \& Johnson, in press; Risser, Hetzel-Riggin, Thomsen, \& McCanne, 2006), and depression and anxiety (Gidycz, Coble, Latham, \& Layman, 1993; Messman-Moore et al., in press) have been associated with increased risk for rape and revictimization. Risser et al. (2006) found that PTSD symptoms mediated the relation between CSA severity and severity of adult sexual assault (ASA) in college women. In a prospective study of community women, Orcutt, Cooper, and Garcia (2005) found that psychological distress and sexual behavior partially mediated the relation between CSA and ASA. These two recent studies are exceptions; few studies have statistically tested for mediation when examining trauma symptoms as a predictor of sexual revictimization (Messman-Moore \& Long, 2003).

Given the high rates of PTSD among individuals reporting CSA (Kessler, Sonnega, Bromet, Hughes, \& Nelson, 1995; Roth, Newman, Pelcovitz, van der Kolk, \& Mandel, 1997), it is not surprising that PTSD has been linked to revictimization in numerous studies. In retrospective studies of college women, PTSD mediated the relationship between CSA and revictimization (Arata, 2000; Risser et al., 2006). Prospective studies have also confirmed the assumption that PTSD increases vulnerability for revictimization (Sandberg, Matorin, \& Lynn, 1999; Messman-Moore, Brown, \& Koelsch, 2005; MessmanMoore, Ward, \& Brown, in press). Researchers are now seeking to identify whether particular aspects of the PTSD construct are associated with increased risk for revictimization. However, only two such studies have been conducted and have not provided consensus in terms of their findings. Risser et al. (2006) examined PTSD as an entity as well as the three symptom clusters separately; in this context, only hyperarousal symptoms predicted revictimization. However, an earlier prospective study found that 
women with high levels of hyperarousal actually had better risk perception in a hypothetical sexual assault scenario, and risk perception predicted revictimization status (Wilson et al., 1999). Another prospective study did not directly compare the predictive power of different aspects of PTSD symptomatology, but did find that intrusive symptoms, emotional numbing/avoidance, dissociation, and hyperarousal symptoms were all associated with victimization (Messman-Moore et al., in press).

\section{Aims of the Present Study}

Taken together, the findings regarding traumatic effects and revictimization suggest that trauma-related symptoms increase risk for rape and revictimization and that one potential mechanism accounting for this relationship is the role of avoidant coping behaviors. Therefore, we proposed that avoidant coping strategies, such as physical isolation, self-blame, and avoiding thinking about the problem-common responses in individuals with a history of CSA - may be maintained according to learning theory principles (i.e., classical and operant conditioning) because trauma-related fears cannot be extinguished. This reliance on avoidant coping perpetuates traumatic symptoms into adulthood, which may place women at increased risk for revictimization by occupying cognitive coping resources. Specifically, in the context of efforts to avoid long-term trauma symptoms, women may be less able to detect and respond effectively to risk-related cues. Consistent with these notions, we proposed a model that predicts revictimization to be an outcome of the impact of coping on trauma symptoms. More specifically, we predicted that CSA severity would predict increased use of avoidant coping, that avoidant coping would predict greater trauma symptoms, and that trauma symptoms would predict sexual revictimization severity. We tested this model in a cross-sectional study of a geographically diverse sample of college women. Undergraduates represent an important population in which to examine these issues given the high rates of sexual assault that occur in this group (Smith, White, \& Holland, 2003). Moreover, CSA has been shown to be associated with depression and anxiety (Briere \& Runtz, 1988), eating disorders (Beckman \& Burns, 1990), ASA (Messman-Moore \& Long, 2000), high risk sexual behaviors (Batten et al., 2001), higher college dropout rates (Duncan, 2000), and substance abuse (see Polusny \& Follette, 1995, for a review) in samples of college women. Although the cross-sectional nature of the study design did not allow for determination of temporal sequence, the use of path analysis determined whether our model fit our theoretical conceptualization of the data.

The current investigation improves upon prior research in this area in several ways. First, it evaluates a more comprehensive model of revictimization that includes four constructs (CSA, adult sexual victimization, coping and trauma symptoms) individually implicated in prior studies but not yet examined together.
Moreover, using a within-subjects design and focusing on CSA severity rather than victim status (abused vs. not) should increase understanding of aspects of CSA that predict revictimization. Third, the current study includes a commonly used measure of coping (Coping Strategies Inventory; Tobin, Holroyd, \& Reynolds, 1984), making results comparable with other similar studies (e.g., Gibson \& Leitenberg, 2001; Santello \& Leitenberg, 1993), and assesses coping specifically in response to CSA rather than general coping (Santello \& Leitenberg, 1993). Finally, the current study adopted a recently recommended analytic approach described by MacKinnon, Lockwood, Hoffman, West, and Sheets (2002) to determine whether mediation occurred, an improvement over many prior studies in this area.

\section{Method}

\section{Participants}

Participants were 99 female undergraduate students who reported a history of CSA. Respondents were recruited from three U.S. universities: University of Southern California (USC), University of Nebraska-Lincoln (UNL), and Miami University (MU) and were part of a larger sample of undergraduates who participated in an investigation of the long-term correlates of CSA. Abuse history was assessed in an initial sample of 1,396 individuals (914 women and 482 men), which yielded the 99 female victims who served as the participants for this study. Male participants were not included in the study because the larger sample yielded only 15 men with a history of sexual abuse, an insufficient number of male participants with which to conduct the analyses. The 99 female participants reported an average age of approximately 21 years (range $=18.18$ to $48.35 ; \mathrm{SD}=3.89$ ). The majority of the sample was European American (64\%), followed by Hispanic/Latina (13\%), African American $(7 \%)$, and Asian American (4\%), and 12 participants who selected "other" to reflect their ethnicity. Most study participants $(85 \%)$ reported that they had never been married. The average family income during childhood reported by participants was between $\$ 50,000-\$ 60,000$; average current family income reported was $\$ 35,000$, indicating that the group was comprised primarily of participants from the midrange of family income.

One goal of collecting data at multiple sites was to achieve a more ethnically diverse sample. Indeed, we found significant differences in ethnicity across the three institutions $\left(\chi^{2}(8, N=99)=31.28, p<.001\right)$. However, analysis of variance and chi-square analyses revealed no differences on the demographic variables of age, income, or marital status. In addition, no significant differences were found across sites for the major study variables of sexual abuse severity, revictimization, or trauma symptoms. One exception was coping, in which participants from MU reported significantly higher use of avoidant coping strategies $(\mathrm{M}=65.44, \mathrm{SD}=13.06)$ compared to both $\mathrm{UNL}$ 
$(\mathrm{M}=54.65, \mathrm{SD}=13.74)$ and $\mathrm{USC}(\mathrm{M}=55.06, \mathrm{SD}=14.71)$ participants, $F(2,109)=3.87, p=.02$. However, the mean coping score from MU was based on a small sample size $(n=13)$ relative to the samples at UNL $(n=37)$ and USC $(n=42)$, and appeared to be driven by a few individuals reporting high levels of avoidant coping.

\section{Measures}

Computer Assisted Maltreatment Inventory (CAMI). The CAMI (DiLillo et al., 2009; DiLillo et al., 2006) is a Web-based, self-report questionnaire designed to assess childhood maltreatment experiences, including sexual abuse, physical abuse, psychological abuse, neglect, and witnessing domestic violence. For the purposes of the current study, only the sexual abuse scale was used because of the consistent links between CSA and revictimization. Participants who reported experiencing sexual touching, sexual kissing, or oral, anal, or vaginal intercourse with a family member or an individual who was five or more years older before the age of 14 , or with someone 10 or more years older when the participant was 14 to 17 years old were classified as victims of sexual abuse. In addition, participants who reported experiencing any of the aforementioned activities against their will, regardless of the difference in age or relationship to the perpetrator, were considered victims of sexual abuse. Voluntary sexual play with a similar age peer, voluntary sexual activities with a dating partner, and noncontact forms of sexual abuse such as exhibitionism were not classified as sexually abusive behavior.

The CAMI yields both a dichotomous variable (presence or absence) of abuse and a continuous abuse severity score. The severity score is a summed composite of six indicators of abuse severity (frequency, duration, nature of the acts, relationship of the perpetrator, force, and number of perpetrators). Similar approaches have been used by Merrill, Thomsen, Sinclair, Gold, and Milner (2001). Items comprising the severity score reflect discrete behavioral features that are not necessarily homogenous (e.g., the relationship with the perpetrator may not relate to the nature of the abusive acts); consequently, coefficient alpha is not applicable. Criterion validity has been assessed by correlating the CAMI sexual abuse severity score with the sexual abuse subscale of the Childhood Trauma Questionnaire (Bernstein \& Fink, 1998; Bernstein et al., 2003), which produced a coefficient of $r=.55$ (computed using the same sample used in the present study) and must be interpreted in light of the differing approaches the scales employ (Likert-type vs. behaviorally specific; DiLillo et al., 2006).

Coping Strategies Inventory (CSI). The CSI (Tobin et al., 1984) is a measure that has been used widely to assess coping strategies in relation to trauma, particularly with survivors of CSA (e.g., Coffey et al., 1996). The CSI contains 72 items that comprise a number of primary, secondary, and tertiary subscales. Here, completion of the CSI was specifically anchored to the sexually abusive experiences reported by participants. That is, only individuals reporting a history of sexual abuse were administered the coping measure, with instructions to complete it specifically in response to their CSA experiences. Because avoidance coping is the most commonly studied coping response in the context of CSA and is both theoretically and empirically linked to negative outcomes among CSA survivors, only the disengagement (i.e., avoidance) subscale was used in the analyses of the present study. This scale reflects attempts to avoid or disengage from the stressful event (e.g., "I hoped a miracle would happen," "I kept my thoughts and feelings to myself") and has been found to have good internal consistency and test-retest reliability (.89 and. 79, respectively; Tobin, Holroyd, Reynolds, \& Wigal, 1989). The CSI also has good criterion and construct validity (Tobin et al., 1989). Internal consistency for the disengagement scale in the present sample was 87 .

Trauma Symptom Checklist-40 (TSC-40). The TSC40 (Briere \& Runtz, 1989; Elliott \& Briere, 1992) is a measure of psychological adjustment that is widely used with survivors of sexual abuse. The TSC- 40 consists of 40 items and was used to assess the frequency of trauma symptoms in the past 2 months. The TSC- 40 has shown predictive validity with regard to a range of traumatic experiences, including intimate partner violence (Dutton, 1995). The TSC Total score was used in this study and has demonstrated strong internal reliability (alphas ranging from .89 to .91; Briere \& Runtz, 1989; Elliott \& Briere, 1992). The internal consistency of the Total Score in the current sample was .92. Of note, avoidance is not assessed by the TSC-40, thus reducing the conceptual overlap between the construct of avoidant coping as a predictor variable and the outcome variable of traumatic distress.

Sexual Experiences Survey (SES). The SES (Koss \& Gidycz, 1985; Koss \& Oros, 1982) was developed to assess unreported rates of sexual assault (e.g., rape and sexual aggression) that occur in the United States. The SES is a 10-item questionnaire in which respondents indicate whether they have experienced a variety of activities of a sexual nature (e.g., kissing, fondling, penetration by an object, rape) associated with varying degrees of coercion, force, and threat. The 10-item SES has demonstrated internal consistency $(r=.74$ for women and $r=$ .89 for men) (Koss \& Gidycz, 1985), and test-retest reliability suggested good concordance rates (93\%). For the purposes of the current study, the SES was expanded to 13 items and the response format modified to 5-point scale $(0=$ never to $4=$ often $)$ to assess two key dimensions (e.g., severity and frequency) of sexual assault incidents. The modified SES provides two subscales in addition to a total score: one subscale reflects experiences of sexual coercion, defined as verbal tactics/pressure for 
unwanted sexual contact, and one subscale pertains to the use of sexual aggression, defined as the use of threat or physical force to obtain unwanted sexual contact. The items comprising the sexual aggression subscale inquire about both attempted and completed sexual assault experiences. Participants were asked to complete the SES to report experiences beginning at age 18; consequently, revictimization events did not overlap with CSA events, which were defined as occurring prior to age 18 .

Each item of the respective SES subscales reflects experiences of increasing severity (e.g., continued pressure to engage in unwanted sexual intercourse to physically forceable rape). Because it is not appropriate to give equal weight to all items on the SES, researchers have developed methods of scoring that involve weighting items according to severity. Consistent with an approach used by Arata and Lindman (2002), the items of each subscale of the SES were weighted in order of severity and then summed for a subscale score. For example, the coercion subscale of the SES consists of five items of increasing severity, such as engaging in unwanted sexual activity because of verbal manipulation (e.g., threats to end relationship, continual pressure). Responses to the first item on the scale were multiplied by one, responses to the second item were multiplied by two, responses to the third item were multiplied by three, and so on. The five weighted items of the coercion subscale were then summed to derive a coercion severity score (range 1575). The same approach was adopted for the aggression subscale, which consists of seven items of increasing severity, such as the threat or use of physical force to obtain unwanted sexual activity, including kissing, fondling, and intercourse (range 28-140). Finally, the two subscales were summed to form a total score (range 43215). Because the items that comprise the SES subscales and total score are behaviorally discrete items ranked in order of intensity from least extreme to most extreme and respondents who agree with a more extreme item tend to also agree with the less extreme items, coefficient alpha is not applicable to this measure and is, therefore, not reported for this sample.

\section{Procedure}

The data collected for this study are part of a larger study examining adult adjustment as a function of childhood maltreatment experiences. Institutional Review Board approval was obtained at all institutions prior to data collection. Participants were recruited in undergraduate psychology courses by trained research assistants. All participants logged onto a common Web site to complete the study measures. The CAMI was presented first, with abuse subscales administered in a random order, followed by random presentation of the additional study measures. Only those participants who endorsed CSA were presented with the measure of coping (CSI) to complete. Respondents received course credit for their participation.

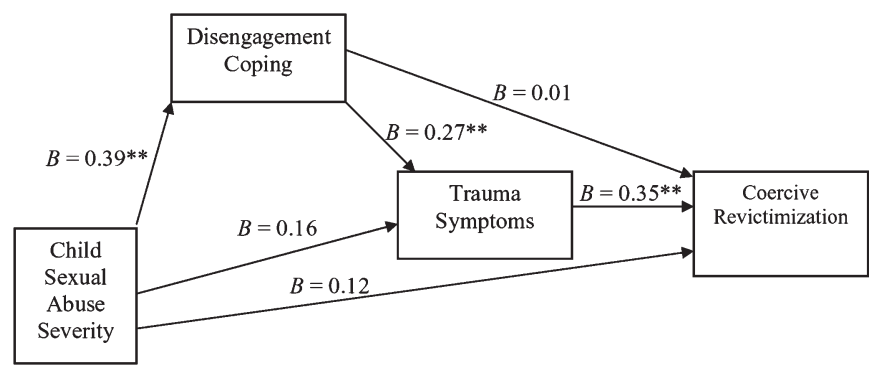

Figure 1. Full path model predicting adult sexual revictimization among women sexually abused in childhood with all direct and indirect paths illustrated. Child sexual abuse $=$ exogenous variable; disengagement coping and trauma symptoms = endogenous variables; revictimization = outcome variable. Standardized coefficients from MPlus output are reported. ${ }^{* *} p<.01$

\section{Data Analysis Strategy}

All analyses were performed using Mplus Version 4.21 statistical analysis software. The path model shown in Figure 1 illustrates how the relationship between CSA severity and subsequent revictimization could be mediated by avoidant coping and trauma symptoms. However, Figure 1 represents a saturated path analysis model with no degrees of freedom that will perfectly, if nonparsimoniously, reproduce all possible bivariate correlations among the four variables. The overall analytic goal was to identify a path model that more parsimoniously described how the childhood sexual abuse severity and subsequent revictimization relationship was mediated by avoidant coping and trauma symptoms. Consistent with this goal, four possible mediation models were identified from Figure 1: (a) CSA severity $\rightarrow$ avoidant coping $\rightarrow$ trauma symptoms, (b) CSA severity $\rightarrow$ trauma symptoms $\rightarrow$ coercive revictimization, (c) CSA severity $\rightarrow$ avoidant coping $\rightarrow$ coercive revictimization, and (d) avoidant coping $\rightarrow$ trauma symptoms $\rightarrow$ coercive revictimization. The four models were tested using the criteria proposed by MacKinnon et al. (2002) for establishing mediation as described below.

In keeping with MacKinnon et al.'s (2002) criteria, all analyses were conducted in two steps. First, direct analyses were conducted to establish a statistically significant IV-DV relationship (i.e., $\tau$ ). Second, mediation analyses were conducted to establish: (1) a statistically significant relationship between the mediator variable and the independent variable (i.e., $\alpha$ ), (2) a statistically significant relationship between the mediator variable and the dependent variable (i.e., $\beta$ ), and (3) a statistically nonsignificant relationship between the independent and dependent variable, controlling for the presence of the mediator variable (i.e., $\boldsymbol{\tau}^{\prime}$ ). All mediation paths (i.e., $\alpha$ and $\beta$ ) were tested for significance using both MacKinnon, Lockwood, and Hoffman's (1998) distribution of products $\left(z_{\alpha} z_{\beta}\right)$ and distribution of $\alpha \beta /$ $\sigma_{\alpha \beta}$ statistical tests (see MacKinnon et al., 2002). Significant mediation results presented below were significant at the $p<0.05$ level according to MacKinnon et al.'s cri- 
Table 1. Correlations Between Coping, Trauma Symptoms, Revictimization, and Abuse Severity

\begin{tabular}{lllllll}
\hline & \multicolumn{1}{c}{ M } & SD & $\begin{array}{c}\text { Disengagement } \\
\text { coping }\end{array}$ & $\begin{array}{c}\text { Trauma } \\
\text { symptoms }\end{array}$ & $\begin{array}{l}\text { Revic- } \\
\text { coercion }\end{array}$ & $\begin{array}{c}\text { Revic- } \\
\text { aggression }\end{array}$ \\
\hline Disengagement coping & 56.67 & 14.57 & & & & \\
revic
\end{tabular}

Revic-coercion = Experience of verbal tactics to obtain unwanted sexual activity; Revic-aggression = Experience of physical harm or threats of physical harm to obtain unwanted sexual activity; Total revic = coercion and aggression subscales combined.

${ }^{*} p<.05 ;{ }^{* *} p<.01$

teria. Specific statistical results are available from the fourth author (see MacKinnon et al., 2002, for details of statistical procedures).

\section{Results}

\section{Sexual Abuse and Revictimization Characteristics}

Average age of the victim at onset of abuse was 8.5 years, with a mean duration of approximately 1.3 years from first to last incident. Approximately $40 \%$ of the participants indicated the most severe act of abuse they endured included intercourse or penetration. Close to half of the respondents $(44 \%)$ indicated that they experienced abuse at the hands of a relative, and most of the perpetrators were male $(89 \%)$. A minority of respondents $(9 \%)$ reported they experienced abuse from a parental figure. The majority of the sample $(80 \%)$ reported only one perpetrator, whereas $20 \%$ reported that they were abused by multiple perpetrators. The use of verbal tactics (e.g., coercion) during the abuse was reported by nearly all participants $(94 \%)$. The threat of violence or use of violence or force was reported by over half of the study sample $(53 \%)$.

Of the 99 participants, the overwhelming majority $(85.9 \%)$ reported experiencing revictimization in the form of sexual coercion in adulthood. More than half of the sample (52.5\%) reported experiencing revictimization in the form of physical aggression as an adult. A total of $10.9 \%$ self-identified as having experienced rape.

\section{Descriptive Data and Associations Among Primary Variables}

Participants reported an average score on the disengagement (i.e., avoidant) coping scale of 56.57 (range 20-86). Trauma symptoms ranged from 3 to 90; the current sample reported levels of symptoms consistent with similar samples of female undergraduates with a CSA history (e.g., Higgins \& McCabe, 1994). CSA severity ranged from 6 to 15 , with an average severity score of $10.25(\mathrm{SD}=2.26)$.
Pearson product-moment correlations between all study measures are reported in Table 1 . As expected, avoidant coping was positively related to CSA severity and trauma symptoms. However, verbal coercion was the only revictimization variable that demonstrated a significant association with other variables of interest. More specifically, verbal coercion severity was significantly (positively) correlated with CSA severity and trauma symptoms, but not with avoidant coping. Because it was expected that revictimization defined as sexual aggression severity would also be correlated with abuse severity, based upon previous research (e.g., Roodman \& Clum, 2001), the sexual aggression subscale of the SES was separated into attempted and completed acts of aggression. However, neither of these scales was significantly associated with CSA severity $(r=.12, p=$ $.28 ; r=.20, p=.06$, respectively), although the completed aggression subscale approached significance. Consequently, severity of verbally coercive revictimization experiences was examined as the outcome variable of interest in the mediational and path analysis presented below.

\section{Mediation Analyses Testing Relationships Between CSA, Avoidant Coping, Trauma Symptoms and Revictimization}

Results of the analyses of the four possible mediation models are shown in Table 2. The full model is shown in Figure 1. Model (a) results show that the relationship between CSA severity and trauma symptoms was fully mediated by avoidant coping. Similarly, model (b) results show that the relationship between CSA severity and coercive revictimization was fully mediated by trauma symptoms. The results of mediation models (a) and (b), taken together, suggest the following sequence of relationships: CSA severity predicts avoidant coping, avoidant coping predicts trauma symptoms, and trauma symptoms predict coercive revictimization severity. Although they failed to meet the mediation criteria set forth by MacKinnon et al. (2002), the results of the final two mediation models provided further support for the aforementioned sequence of relationships. 
Table 2. Results of Mediation Analyses

\begin{tabular}{|c|c|c|c|c|}
\hline Models & $b$ & S.E. & Wald Z & $\beta$ \\
\hline CSA severity $\rightarrow$ trauma symptoms $(\tau)$ & 2.40 & 0.91 & $2.64^{* *}$ & 0.27 \\
\hline CSA severity $\rightarrow$ disengagement coping $(\boldsymbol{\alpha})$ & 2.54 & 0.61 & $4.16^{\star *}$ & 0.39 \\
\hline disengagement coping $\rightarrow$ trauma symptoms $(\boldsymbol{\beta})$ & 0.37 & 0.14 & $2.60^{* *}$ & 0.27 \\
\hline CSA severity $\rightarrow$ trauma symptoms $\left(\tau^{\prime}\right)$ & 1.45 & 0.95 & $1.52^{* *}$ & 0.16 \\
\hline \multicolumn{5}{|l|}{ Model (b): mediation analyses } \\
\hline CSA severity $\rightarrow$ trauma symptoms $(\boldsymbol{\alpha})$ & 2.40 & 0.91 & $2.64^{* *}$ & 0.27 \\
\hline trauma symptoms $\rightarrow$ coercive revictimization $(\boldsymbol{\beta})$ & 0.18 & 0.05 & $3.54^{\star *}$ & 0.35 \\
\hline CSA severity $\rightarrow$ coercive revictimization $\left(\tau^{\prime}\right)$ & 0.56 & 0.47 & $1.18^{* *}$ & 0.12 \\
\hline \multicolumn{5}{|l|}{ Model (c): direct analysis } \\
\hline CSA severity $\rightarrow$ coercive revictimization $(\tau)$ & 0.99 & 0.49 & $2.03^{* *}$ & 0.21 \\
\hline \multicolumn{5}{|l|}{ Model (d): direct analysis } \\
\hline disengagement coping $\rightarrow$ coercive revictimization $(\tau)$ & 0.12 & 0.07 & $1.61^{* *}$ & 0.16 \\
\hline
\end{tabular}

${ }^{*} p<.05 ;{ }^{* *} p<.01$

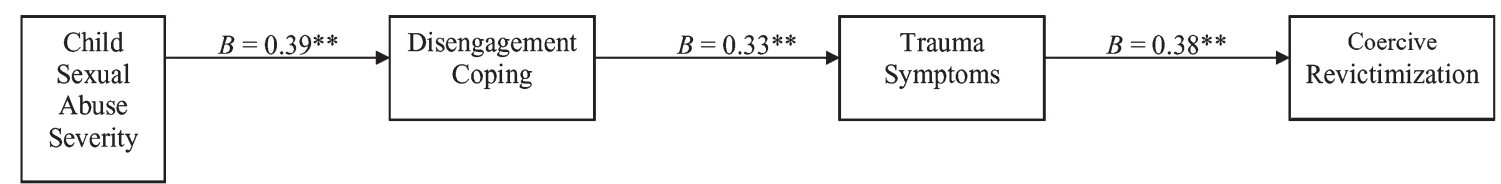

Figure 2. Reduced path model predicting adult sexual revictimization among women sexually abused in childhood with only significant paths illustrated. Child sexual abuse = exogenous variable; disengagement coping and trauma symptoms = endogenous variables; revictimization $=$ outcome variable. Standardized coefficients from MPlus output are reported. ${ }^{* *} p<.01$.

Specifically, model (c) failed to meet mediation criteria because only the relationship between CSA severity and avoidant coping was statistically significant. Further, the effect of trauma symptoms as a mediator of the relationship between avoidant coping and coercive revictimization could not be tested because the relationship between avoidant coping and coercive revictimization was statistically nonsignificant (i.e., the relationship between avoidant coping and coercive revictimization must include trauma symptoms as a mediator consistent with the results of model [b]). Therefore, consistent with prior research (Fondacaro \& Moos, 1989; Holahan \& Moos, 1987), the results from both the statistically significant and statistically nonsignificant mediation analyses, when examined together, suggested the sequential predictive model shown in Figure 2. Finally, the full model shown in Figure 1 and the sequential predictive model shown in Figure 2 were compared using a nested model test to determine which model better fit the data. Specifically, the difference between the chi-square model fit statistics for the sequential predictive model and the full model (i.e., 3.68 minus 0 , respectively) was tested against a chi-square distribution at degrees of freedom equal to the difference in degrees of freedom between the sequential predictive model and the full model (i.e., 3 minus 0 , respectively). The nested model test was statistically nonsignificant (i.e., $\chi_{3}^{2}=3.68, p=0.30$ ), which indicated that the sequential predictive model did not fit the data significantly differently from the full model shown in Figure 1. As a result, the more parsimonious sequential predictive model was retained $($ RMSEA $=$ 0.048; $\mathrm{SRMR}=0.058 ; \mathrm{CFI}=0.98$ ).

\section{Discussion}

Results of the present investigation are consistent with past research examining the smaller mediational models tested in our study: avoidant coping as a mediator of the relation between CSA and trauma symptoms (e.g., Brand \& Alexander, 2003) and trauma symptoms as a mediator of the relation between CSA and sexual revictimization (e.g., Risser et al., 2006). However, the interface between avoidant coping and trauma symp- 
toms had not previously been considered as a means of understanding pathways to sexual revictimization. The purpose of this investigation was to extend prior findings by examining a more comprehensive model of the CSA-revictimization relationship that included avoidant coping and trauma symptoms in a manner that would statistically test for mediation (e.g., MacKinnon et al., 2002). Here, CSA severity predicted avoidant coping, which was associated with increased trauma symptoms, a variable that was, in turn, predictive of severity of coercive sexual revictimization. This model helps clarify the relationships among variables that appear to be important in understanding the increased rates of revictimization among CSA survivors. Specifically, it appears that early sexual abuse may operate indirectly, through avoidant coping and trauma symptoms, to increase the risk of coercive sexual victimization in adulthood.

Recent data suggest that, among various risk factors for revictimization (e.g., coping, PTSD symptoms, selfblame), avoidant coping may be an important predictor of adult revictimization severity (Filipas \& Ullman, 2006). The present findings are consistent with this possibility. However, whereas our model indicates that avoidant coping may lead to trauma symptoms in predicting severity of coercive revictimization, some researchers have found that trauma symptoms precede problematic outcomes associated with avoidant coping, such as impaired self-functioning (e.g., dysfunctional sexual behavior, tension-reducing behavior, impaired self-reference; Messman-Moore et al., 2005). These inconsistent findings have several implications. First, the associations between distress and risk variables such as avoidant coping are likely to be complex in nature. It may be, for example, that avoidant coping and trauma symptoms - both correlates of abuse history - are mutually influential and work in multiple ways to impact sexual revictimization. For instance, it is possible that different types of distress related to a history of sexual abuse (e.g., PTSD symptoms) lead to dysfunctional coping behaviors (e.g., avoidance, withdrawal) that are then related to difficulties in self-regulation (e.g., risky sexual behavior, substance abuse), which predict revictimization (Messman-Moore et al., 2005). Second, these inconsistencies point to potential differences regarding the manner in which coping has been operationalized in the extant literature. Coping comprises a range of responses, including both behaviors and cognitions. For example, behavioral coping strategies (e.g., substance use), such as those assessed by Filipas and Ullman (2006) and Messman-Moore et al. (2005), likely emanate from traumatic symptoms. Conversely, in the present study, coping was defined as cognitions reflecting a desire to avoid and was found to precede trauma symptoms, a finding consistent with a cognitive model of psychopathology (e.g., Beck, 1964).

Results of the current study have implications for determining which CSA survivors may be at risk for revictimization later in life. Specifically, it is not simply the presence of early sexual abuse that places one at risk for future sexual assault, but the severity of abuse, which impacts the intermediary factors of coping and overall traumatic distress. Moreover, increasing abuse severity was related to the occurrence of increasing sexually coercive experiences, but not sexually aggressive revictimization. This finding is contrary to Roodman and Clum's (2001) meta-analysis, which found that more severe CSA was related to more severe revictimization. Although a significant association between abuse severity and later sexual aggression was not found in the present study, we cannot rule out that this relationship exists. This inconsistency may be due to the low number of self-reported rape survivors identified in the present study, which may have limited our ability to detect associations with CSA severity. In fact, the relationship between CSA and aggressive revictimization in the present study approached significance even with the low number of participants who reported rape experiences $(n=$ 11). Further, we did not examine instances of adolescent sexual assault (e.g., with a similar age peer), which have been found to be particularly strong predictors of adult revictimization (Humphrey \& White, 2000).

Nevertheless, the present results are consistent with a growing set of findings suggesting differential risk factors for victimization defined as coercion versus victimization classified as rape. For example, low self-esteem (Testa \& Dermen, 1999; Zweig, Barber, \& Eccles, 1997), social anxiety and depression (Zweig et al., 1997), and self-criticism (Messman-Moore, Coates et al., in press) have been found to predict sexual coercion specifically, whereas alcohol and marijuana use and dissociation may be more closely linked to rape (Messman-Moore, Coates et al., 2008). In addition, it is possible that CSA severity was not related to aggressive revictimization in our sample because verbally coercive revictimization, which was associated with CSA, typically involves a perpetrator that is known to the victim (i.e., dating partner; Messman-Moore \& Long, 2000) and known perpetrators rarely use serious physical force (Lyndon, White, \& Kadlec, 2007). There is also corresponding evidence that intervention programs with college students may be more effective in reducing coercive revictimization than in preventing rape (Marx, Calhoun, Wilson, \& Meyerson, 2001).

The current study has limitations that suggest directions for future research. Although our sample of college students was geographically and ethnically diverse, they were relatively homogeneous with respect to age and education level, making generalization of findings to more heterogeneous samples difficult. Nonetheless, college women represent an extremely important group to study in the context of sexual abuse because of the high risk of assault in this age group. In fact, in a large sample of over 1,500 undergraduate females, Smith and colleagues (2003) found that $88 \%$ of women experienced physical or sexual violence between adolescence and the 
fourth college year. Moreover, the experience of sexual abuse in adolescence places women at greater risk for sexual assault in college. Therefore, understanding the links between a history of CSA and revictimization in college women is an important area of study.

Additional limitations are the inclusion of only women and the examination of a limited number of variables that may be relevant to the CSA-revictimization relationship. Future investigations should clarify the potential moderating effects of age, education, and gender in predicting revictimization. Similarly, there is a need to consider the role of coping and trauma symptoms within the broader context of other mediating factors that have been linked to revictimization (e.g., substance use, risk recognition, interpersonal difficulties). Little is known, as well, about the larger social and cultural factors that may be related to revictimization; hence, a broader ecological perspective will be important to understand the broader context of revictimization (Messman-Moore \& Long, 2003).

Finally, our data were collected retrospectively and analyzed within a cross-sectional, correlational design, which does not allow for a determination of causal relationships among variables. Thus, as noted earlier, although the present findings suggest that coping strategies may precede the emergence of long-term trauma symptomatology, it may be that elevated trauma symptomatology pre-dates avoidant coping, or that, for some women, increased trauma symptomatology is confounded with revictimization. Although we cannot determine temporal sequencing in the present investigation, the use of path analyses provides an opportunity to examine the plausibility of the conceptualized model and relationships. Nonetheless, longitudinal studies are needed to clarify temporal sequencing and evaluate causal associations. Moreover, these studies should include variables such as self-esteem, social anxiety, depression, self-criticism, and substance use, which may be helpful in distinguishing the risk factors associated with revictimization in the form of sexual coercion and more severe aggression (e.g., Messman-Moore, Coates et al., 2008). However, because longitudinal studies are time and labor intensive, process-oriented methods that permit the study of changes in coping and adaptation over time may be useful as well (Tennen, Affleck, Armeli, \& Carney, 2000). Using this approach, adult participants could provide abuse history retrospectively yet report coping strategies on a daily basis so that fluctuations in functioning are assessed contemporaneously with coping.

The present findings suggest that coping processes and trauma symptoms should be viewed as part of the constellation of modifiable factors that place women at increased risk for coercive revictimization. Avoidant coping may be especially important to consider therapeutically because of its possible role as a determinant of trauma symptoms leading to revictimization. This assertion is supported by a growing emphasis in the treatment literature on coping processes as a component of effective interventions with adult survivors of rape and sexual abuse, including those that target abuse-related negative affect (e.g., Skills Training in Affect and Interpersonal Regulation; Cloitre, 1998) and cognitive coping (e.g., Cognitive Processing Therapy, Chard, 2005; Resick \& Schnike, 1992). Thus, efforts to decrease the use of avoidant coping (e.g., withdrawal, substance abuse, repression) in the long-term should be considered as a part of treatment protocols used with sexual abuse survivors. Aside from intervening to improve coping responses, the reduction and management of traumatic symptoms is also an important goal to incorporate into abuse-focused interventions. The relief of these symptoms may also reduce risk of coercive revictimization. Future research is needed to clarify the specific contributions of avoidant coping and trauma symptoms to increased risk of verbally coercive revictimization. Several hypotheses emerge, including the impact of dissociation on the ability to detect risk cues, the use of avoidance as protection from injury, and the internalization that unwanted sexual experiences are the norm and that resistance is futile based on childhood experiences. Research that identifies the mechanisms that explain the connection between avoidance and revictimization will further inform intervention efforts.

\section{References}

Arata, C. M. (1999a). Coping with rape: The roles of prior sexual abuse and attributions of blame. Journal of Interpersonal Violence, 14, 62-78.

Arata, C. M. (1999b). Repeated sexual victimization and mental disorders in women. Journal of Child Sexual Abuse, 7, 1-17.

Arata, C. M. (2000). From child abuse victim to adult victim: A model for predicting sexual revictimization. Child Maltreatment, 5, 28-38.

Arata, C. M. (2002). Child sexual abuse and sexual revictimization. Clinical Psychology: Science \& Practice, 9, 135-164.

Arata, C. M., Lindman, L. (2002). Marriage, child abuse, and sexual revictimization. Journal of Interpersonal Violence, 17, 953-971.

Arias, I., Pape, K. T. (1999). Psychological abuse: Implications for adjustment and commitment to leave violence partners. Violence and Victims, 14, 55-67.

Badura, A. S. (2003). Theoretical and empirical exploration of the similarities between emotional numbing in posttraumatic stress disorder and alexithymia. Journal of Anxiety Disorders, 17, 349-360.

Batten, S. V., Follette, V. M., Aban, I. B. (2001). Experiential avoidance and high-risk sexual behavior in survivors of child sexual abuse. Journal of Child Sexual Abuse, 10, 101-120.

Beck, A. T. (1964). Thinking and depression: II. Theory and therapy. Archives of General Psychiatry, 10, 561-571. 
Beckman, K. A., Burns, G. L. (1990). Relation of sexual abuse and bulimia in college women. International Journal of Eating Disorders, 9, 487-492.

Benotsch, E. G., Brailey, K., Vasterling, J. J., Uddo, M. M., Constans, J. I., Sutker, P. B. (2000). War zone stress, personal and environmental resources, and PTSD symptoms in Gulf War veterans: A longitudinal perspective. Journal of Abnormal Psychology, 109, 205-213.

Bernstein, D., Fink, L. (1998). Childhood Trauma Questionnaire: A retrospective self-report . San Antonio, TX : The Psychological Corporation.

Bernstein, D. P., Stein, J. A., Newcomb, M. D., Walker, E., Pogge, D., Ahluvalia, T., et al. (2003). Development and validation of a brief screening version of the Childhood Trauma Questionnaire. Child Abuse and Neglect, 27, 169-190.

Boeschen, L. E., Koss, M. P., Figueredo, A. J., Coan, J. A. (2001). Experiential avoidance and post-traumatic stress disorder: A cognitive mediational model of rape recovery. Journal of Aggression, Maltreatment \& Trauma, 4, 211-245.

Bonanno, G. A., Noil, J. G., Putnam, F. W., O'Neill, M., Trickett, P. K. (2003). Predicting the willingness to disclose childhood sexual abuse from measures of repressive coping and dissociative tendencies. Child Maltreatment, 8, 302-318.

Brand, B. L., Alexander, P. C. (2003). Coping with incest: The relationships between recollections of childhood coping and adult functioning in female survivors of incest. Journal of Traumatic Stress, 16, 285-293.

Briere, J., Runtz, M. (1988). Symptomatology associated with childhood sexual victimization in a nonclinical adult sample. Child Abuse and Neglect, 12, 51-59.

Briere, J., Runtz, M. (1989). The Trauma Symptom Checklist (TSC-33). Early data on a new scale. Journal of Interpersonal Violence, 8, 151-163.

Bryant, R. A., Harvey, A. G. (1995). Avoidant coping style and post-traumatic stress following motor vehicle accidents. Behaviour Research \& Therapy, 33, 631-635.

Chard, K. M. (2005). An evaluation of cognitive processing therapy for the treatment of posttraumatic stress disorder related to childhood sexual abuse. Journal of Consulting and Clinical Psychology, 73, 965-971.

Chu, J. A. (1992). The revictimization of adult women with histories of childhood abuse. Journal of Psychotherapy Practice \& Research, 1, 259-269.

Classen, C. C., Palesh, O. G., Aggarwal, R. (2005). Sexual revictimization: A review of the empirical literature. Trauma, Violence \& Abuse, 6, 103-129.

Cloitre, M. (1998). Sexual revictimization: Risk factors and prevention. In: V. M. Follette J. I. Ruzek (Eds.), Cognitive-behavioral therapies for trauma (pp. 278-304). New York : Guilford.

Cloitre, M. Rosenberg, A. (2006). Sexual revictimization: Risk factors and prevention. In V. M. Follette J. I. Ruzek (Eds.), Cognitive-behavioral therapies for trauma (pp. 321-361). New York : Guilford.

Cloitre, M., Scarvalone, P., Difede, J. (1997). Posttraumatic stress disorder, self- and interpersonal dysfunction among sexually retraumatized women. Journal of Traumatic Stress, 10, 437-452.

Coffey, P., Leitenberg, H., Henning, K., Turner, T., Bennett, R. T. (1996). The relation between methods of coping during adulthood with a history of childhood sexual abuse and current psychological adjustment. Journal of Consulting and Clinical Psychology, 64, 1090-1093.

Coyne, J. C., Racioppo, M. W. (2000). Never the twain shall meet? Closing the gap between coping research and clinical intervention research. American Psychologist, 55, 655-664.

DiLillo, D. (2001). Interpersonal functioning among women reporting a history of childhood sexual abuse: Empirical findings and methodological issues. Clinical Psychology Review, 21, 553-576.

DiLillo, D., Fortier, M. A., Hayes, S. A., Trask, E., Perry, A. R., Messman-Moore, T. L., et al. (2006). Retrospective assessment of childhood sexual and physical abuse: A comparison of scaled and behaviorally specific approaches. Assessment, 13, 297-312.

DiLillo, D., Hayes, S., Fortier, M. A., Perry, A. R., Evans, S., Messman-Moore, T. L., et al. (2009). Development and initial psychometric properties of the Computer Assisted Maltreatment Inventory (CAMI): A comprehensive selfreport measure of child maltreatment history. Manuscript submitted for publication.

DiPalma, L. M. (1994). Patterns of coping and characteristics of high-functioning incest survivors. Archives of Psychiatric Nursing, 8 (2), 82-90.

Duncan, R. D. (2000). Childhood maltreatment and college drop-out rates: Implications for child abuse researchers. Journal of Interpersonal Violence, 15, 987-995.

Dunmore, E., Clark, D. M., Ehlers, A. (1999). Cognitive factors involved in the onset and maintenance of posttraumatic stress disorder (PTSD) after physical or sexual assault. Behaviour Research and Therapy, 37, 809-829.

Dutton, D. G. (1995). Intimate abusiveness. Clinical Psychology: Science \& Practice, 2, 207-224.

Ehlers, A., Clark, D. M. (2000). A cognitive model of posttraumatic stress disorder. Behaviour Research and Therapy, 38, 319-345.

Elliott, D. M., Briere, J. (1992). Sexual trauma among professional women: Validating the Trauma Symptom Checklist40. Child Abuse and Neglect, 16, 391-398.

Elliott, D. M., Briere, J. (1995). Posttraumatic stress associated with delayed recall of sexual abuse: A general population study. Journal of Traumatic Stress, 3, 629-648.

Filipas, H. H., Ullman, S. E. (2006). Child sexual abuse, coping responses, self-blame, posttraumatic stress disorder, and adult sexual revictimization. Journal of Interpersonal Violence, 21, 652-672.

Finkelhor, D. (1994). Current information on the scope and nature of child abuse. The Future of Children, 4, 31-53.

Foa, E. B., Kozak, M. J. (1986). Emotional processing of fear: Exposure to corrective information. Psychological Bulletin, 99, 20-35.

Fondacaro, M. R., Moos, R. H. (1989). Life stressors and coping: A longitudinal analysis among depressed and nondepressed adults. Journal of Community Psychology, 17, 330-340.

Futa, K. T., Nash, C. L., Hansen, D. J., Garbin, C. P. (2003). Adult survivors of childhood abuse: An analysis of coping mechanisms used for stressful childhood memories and current stressors. Journal of Family Violence, 18, 227-239.

Gibson, L. E., Leitenberg, H. (2001). The impact of child sexual abuse and stigma on methods of coping with sexual assault among undergraduate women. Child Abuse and Neglect, 25, 1343-1361. 
Gidycz, C. A., Coble, C. N., Latham, L., Layman, M. J. (1993). Sexual assault experience in adulthood and prior victimization experiences: A prospective analysis. Psychology of Women Quarterly, 17, 151-168.

Hayes, S. C., Strosahl, K., Wilson, K. G. (1999). Acceptance and commitment therapy: Understanding and treating human suffering. New York: Guilford.

Hayes, S. C., Wilson, K. G., Gifford, E. V., Follette, V. M., Strosahl, K. (1996). Experiential avoidance and behavioral disorders: A functional dimensional approach to diagnosis and treatment. Journal of Consulting and Clinical Psychology, 64, 1152-1168.

Higgins, D. J., McCabe, M. P. (1994). The relationship of child sexual abuse and family violence to adult adjustment: Toward an integrated risk-sequelae model. Journal of Sex Research, 31, 255-266.

Holahan, C. J., Moos, R. H. (1987). Personal and contextual determinants of coping strategies. Journal of Personality \& Social Psychology, 52, 946-955.

Humphrey, J. A., White, J. W. (2000). Women's vulnerability to sexual assault from adolescence to young adulthood. Journal of Adolescent Health, 27, 419-424.

Johnson, B. K., Kenkel, M. B. (1991). Stress, coping, and adjustment in female adolescent incest victims. Child Abuse \& Neglect, 15, 293-305.

Johnson, D. M., Sheahan, T. C., Chard, K. M. (2003). Personality disorders, coping strategies, and posttraumatic stress disorder in women with histories of childhood sexual abuse. Journal of Child Sexual Abuse, 12 (2), 19-39.

Keane, T. M., Fairbank, J. A., Caddel, J. M., Zimering, R. T., Bender, M. E. (1985). A behavioral approach to assessing and treating post-traumatic stress disorder in Vietnam veterans. In C. R. Figley (Ed), Trauma and its wake (pp. 257294). New York: Brunner/Mazel.

Kessler, R. C., Sonnega, A., Bromet, E., Hughes, M., Nelson, C. (1995). Posttraumatic stress disorder in the National Comorbidity Survey. Archives of General Psychiatry, 52, 1048-1060.

Kilpatrick, D. G., Acierno, R., Resnick, H. S., Saunders, B. E., Best, C. L. (1997). A 2-year longitudinal analysis of the relationship between violent assault and substance use in women. Journal of Consulting and Clinical Psychology, 65, 834-847.

Kleber, R. J., Brown, D. (1992). Coping with trauma: Theory, prevention, and treatment. Amsterdam : Swets and Zeitlinge.

Koss, M. P., Gidycz, C. A. (1985). Sexual experiences survey: Reliability and validity. Journal of Consulting and Clinical Psychology, 53, 422-423.

Koss, M. P., Oros, C. J. (1982). Sexual experiences survey: A research instrument investigating sexual aggression and victimization. Journal of Consulting and Clinical Psychology, 50, 455-457.

Krause, E. D., Kaltman, S., Goodman, L. A., Dutton, M. A. (2008). Avoidant coping and PTSD symptoms related to domestic violence exposure: A longitudinal study. Journal of Traumatic Stress, 21, 83-90.

Leitenberg, H., Greenwald, E., Cado, S. (1992). A retrospective study of long-term methods of coping with having been sexually abused during childhood. Child Abuse \& Neglect, $16,399-407$.

Littleton, H., Horsley, S., John, S., Nelson, D. V. (2007). Trauma coping strategies and psychological distress: A meta-analysis. Journal of Traumatic Stress, 20, 977-988.
Litz, B. T., Gray, M. J. (2002). Emotional numbing in posttraumatic stress disorder: Current and future research directions. Australian and New Zealand Journal of Psychiatry, 36, 198-204.

Lyndon, A. E., White, J. W., Kadlec, K. M. (2007). Manipulation and force as sexual coercion tactics: Conceptual and empirical differences. Aggressive Behavior, 33, 291-303.

MacKinnon, D. P., Lockwood, C. M., Hoffman, J. M. (1998, June). A new method to test for mediation . Paper presented at the annual meeting of the Society for Prevention Research, Park City, UT .

MacKinnon, D. P., Lockwood, C. M., Hoffman, J. M., West, S. G., Sheets, V. (2002). A comparison of methods to test mediation and other intervening variable effects. Psychological Methods, 7, 83-104.

Marx, B. P., Calhoun, K. S., Wilson, A. E., Meyerson, L. A. (2001). Sexual revictimization prevention: An outcome evaluation. Journal of Consulting and Clinical Psychology, 69, 25-32.

Mellman, T. A., David, D., Bustamante, V., Fins, A. I., Esposito, K. (2001). Predictors of post-traumatic stress disorder following severe injury. Depression \& Anxiety, 14, 226-231.

Merrill, L. L., Thomsen, C. J., Sinclair, B. B., Gold, S. R., Milner, J. S. (2001). Predicting the impact of child sexual abuse on women: The role of abuse severity, parental support, and coping strategies. Journal of Consulting and Clinical Psychology, 69, 992-1006.

Messman-Moore, T. L., Brown, A. L., Koelsch, L. E. (2005). Posttraumatic symptoms and self-dysfunction as consequences and predictors of sexual revictimization. Journal of Traumatic Stress, 18, 253-261.

Messman-Moore, T. L., Coates, A. A., Gaffey, K. J., Johnson, C. F. (2008). Sexuality, substance use, and susceptibility to victimization: Risk for rape and sexual coercion in a prospective study of college women. Journal of Interpersonal Violence, 23, 1730-1746.

Messman-Moore, T. L., Long, P. J. (2000). Child sexual abuse and revictimization in the form of ASA, adult physical abuse, and adult psychological maltreatment. Journal of Interpersonal Violence, 15, 489-502.

Messman-Moore, T. L., Long, P. J. (2003). The role of childhood sexual abuse sequelae in sexual revictimization: An empirical review and theoretical reformulation. Clinical Psychology Review, 23, 537-571.

Messman-Moore, T. L., Long, P. J., Siegfried, N. J. (2000). The revictimization of child sexual abuse survivors: An examination of the adjustment of college women with child sexual abuse, adult sexual assault, and adult physical abuse. Child Maltreatment, 5, 18-27.

Messman-Moore, T. L., Ward, R. M., Brown, A. L. (2009). Substance use and PTSD symptoms impact the likelihood of rape and revictimization in college women. Journal of Interpersonal Violence, 24, 499-521.

Molnar, B. E., Buka, S. L., Kessler, R. C. (2001). Child sexual abuse and subsequent psychopathology: Results from the National Comorbidity Survey. American Journal of Public Health, 91, 753-760.

Mowrer, O. H. (1960). Learning theory and behavior . New York: Wiley.

Neumann, D. A., Houskamp, B. M., Pollock, V. E., Briere, J. (1996). The long term sequelae of childhood sexual abuse in women: A meta-analytic review. Child Maltreatment, 1, 6-16. 
Oaksford, K., Frude, N. (2003). The process of coping following child sexual abuse: A qualitative study. Journal of Child Sexual Abuse, 12 (2), 41-72.

Orcutt, H. K., Cooper, M. L., Garcia, M. (2005). Use of sexual intercourse to reduce negative affect as a prospective mediator of sexual revictimization. Journal of Traumatic Stress, $18,729-739$.

Polusny, M. A., Follette, V. M. (1995). Long-term correlates of child sexual abuse: Theory and review of the empirical literature. Applied and Preventive Psychology, 4, 143-166.

Polusny, M. A., Rosenthal, M. Z., Aban, I., Follette, V. M. (2004). Experimental avoidance as a mediator of the effects of adolescent sexual victimization on negative adult outcomes. Violence and Victims, 19, 109-120.

Rauch, S., Foa, E. (2006). Emotional processing theory (EPT) and exposure therapy for PTSD. Journal of Contemporary Psychotherapy, 36, 61-65.

Resick, P. A., Schnicke, M. K. (1992). Cognitive processing therapy for sexual assault victims. Journal of Consulting and Clinical Psychology, 60, 748-756.

Risser, H. J., Hetzel-Riggin, M. D., Thomsen, C. J., McCanne, T. R. (2006). PTSD as a mediator of sexual revictimization: The role of reexperiencing, avoidance, and arousal symptoms. Journal of Traumatic Stress, 19, 687-698.

Roodman, A. A., Clum, G. A. (2001). Revictimization rates and method variance: A meta-analysis. Clinical Psychology Review, 21, 183-204.

Rosenthal, M. Z., Cheavens, J. S., Lynch, T. R., Follette, V. (2006). Thought suppression mediates the relationship between negative mood and PTSD in sexually assaulted women. Journal of Traumatic Stress, 19, 741-745.

Roth, S., Newman, E., Pelcovitz, D., Van Der Kolk, B., Mandel, F. S. (1997). Complex PTSD in victims exposed to sexual and physical abuse: Results from the DSM-IV field trial for posttraumatic stress disorder. Journal of Traumatic Stress, 10, 539-555.

Sandberg, D. A., Matorin, A. I., Lynn, S. J. (1999). Dissociation, posttraumatic symptomatology, and sexual revictimization: A prospective examination of mediator and moderator effects. Journal of Traumatic Stress, 12, 127-138.

Santello, M. D., Leitenberg, H. (1993). Sexual aggression by an acquaintance: Methods of coping and later psychological adjustment. Violence and Victims, 8, 91-104.

Sharkansky, E. J., King, D. W., King, L. A., Wolfe, J. (2000). Coping with Gulf War combat stress: Mediating and moderating effects. Journal of Abnormal Psychology, 109, 188-197.
Shipherd, J. C., Beck, J. G. (1999). The effects of suppressing trauma-related thoughts on women with rape-related posttraumatic stress disorder. Behaviour Research and Therapy, 37, 99-112.

Smith, P. H., White, J. W., Holland, L. J. (2003). A longitudinal perspective on dating violence among adolescent and college-age women. American Journal of Public Health, 93, 1104-1109.

Sutker, P. B., Davis, J. M., Uddo, M. M., Ditta, S. R. (1995). War zone stress, personal resources, and PTSD in Persian Gulf War returnees. Journal of Abnormal Psychology, 104, 444-452.

Tennen, H., Affleck, G., Armeli, S., Carney, M. A. (2000). A daily process approach to coping: Linking theory, research, and practice. American Psychologist, 55, 626-636.

Testa, M., Dermen, K. H. (1999). The differential correlates of sexual coercion and rape. Journal of Interpersonal Violence, $14,548-561$.

Tobin, D. L., Holroyd, K. A., Reynolds, R. V. (1984). User's manual for the Coping Strategies Inventory . Athens, $\mathrm{OH}$ : Ohio University, Department of Psychology.

Tobin, D. L., Holroyd, K. A., Reynolds, R. V., Wigal, J. K. (1989). The hierarchical factor structure of the Coping Strategies Inventory. Cognitive Therapy and Research, 13, 343-361.

Valentiner, D. P., Foa, E. B., Riggs, D. S., Gershuny, B. S. (1996). Coping strategies and posttraumatic stress disorder in female victims of sexual and nonsexual assault. Journal of Abnormal Psychology, 105, 455-458.

Wilson, A. E., Calhoun, K. S., Bernat, J. A. (1999). Risk recognition and trauma-related symptoms among sexually revictimized women. Journal of Consulting and Clinical Psychology, 67, 705-710.

Yehuda, R., Steiner, A., Kahana, B., Binder-Brynes, K., Southwick, S. M., Zemelman, S., et al. (1997). Alexithymia in Holocaust survivors with and without PTSD. Journal of Traumatic Stress, 10, 93-100.

Zlotnick, C., Mattia, J. I., Zimmerman, M. (2001). The relationship between posttraumatic stress disorder, childhood trauma and alexithymia in an outpatient sample. Journal of Traumatic Stress, 14, 177-188.

Zweig, J. M., Barber, B. L., Eccles, J. S. (1997). Sexual coercion and well-being in young adulthood: Comparisons by gender and college status. Journal of Interpersonal Violence, 12, 291-308. 